\title{
A progressive declining in the burden of malaria in north-eastern Tanzania
}

\author{
Bruno P Mmbando ${ }^{1,2}$, Lasse S Vestergaard ${ }^{3}$, Andrew Y Kitua ${ }^{4}$, Martha M Lemnge ${ }^{1}$, Thor G Theander ${ }^{3}$, \\ John PA Lusingu ${ }^{1 *}$
}

\begin{abstract}
Background: The planning and assessment of malaria interventions is complicated due to fluctuations in the burden of malaria over time. Recently, it has been reported that the burden of malaria in some parts of Africa has declined. However, community-based longitudinal data are sparse and the reasons for the apparent decline are not well understood.
\end{abstract}

Methods: Malaria prevalence and morbidity have been monitored in two villages in north-eastern Tanzania; a lowland village and a highland village from 2003 to 2008. Trained village health workers treated presumptive malaria with the Tanzanian first-line anti-malarial drug and collected blood smears that were examined later. The prevalence of malaria parasitaemia across years was monitored through cross-sectional surveys.

Results: The prevalence of malaria parasitaemia in the lowland village decreased from $78.4 \%$ in 2003 to $13.0 \%$ in 2008, whereas in the highland village, the prevalence of parasitaemia dropped from $24.7 \%$ to $3.1 \%$ in the same period. Similarly, the incidence of febrile malaria episodes in the two villages dropped by almost $85 \%$ during the same period and there was a marked reduction in the number of young children who suffered from anaemia in the lowland village.

Conclusion: There has been a marked decline in malaria in the study villages during the past few years. This decline is likely to be due to a combination of factors that include improved access to malaria treatment provided by the trained village helpers, protection from mosquitoes by increased availability of insecticide-impregnated bed nets and a reduced vector density. If this decline in malaria morbidity is sustained, it will have a marked effect on the disease burden in this part of Tanzania.

\section{Background}

There have been previous efforts to eradicate or, if this was not possible, to eliminate malaria, but these ambitious goals have not been achieved in large parts of Africa [1-5] despite the development of effective tools, such as insecticide-impregnated bed nets (ITNs) and case management on demand; and malaria vaccines are being developed to complement the existing tools [6-9]. The performance of these tools can be monitored by careful surveillance of the malaria burden in a defined community before and after their deployment [10-12]. However, malaria transmission and the associated disease burden can fluctuate in the absence of any intervention due to climatic variations and societal

\footnotetext{
* Correspondence: jpalusingu@yahoo.co.uk ${ }^{1}$ National Institute for Medical Research, Tanga Centre, Tanga, Tanzania
}

behavioural changes. These changes can be dramatic in areas of unstable and seasonal malaria transmission, but are much less pronounced in areas of high and stable transmission $[13,14]$. In the past few years, reports have documented that the malaria burden has diminished in several areas of Africa [15-18], but the reasons for these changes are still uncertain. This fortunate development has been ascribed to a combination of interventions, such as use of ITNs, artemisinin combination therapy (ACT) and indoor residual spraying (IRS) [16]. This paper documents a marked decline in the malaria burden in two Tanzanian villages in an area with stable malaria transmission during the period 2003 to 2008 . The decrease was most marked in a village where transmission was high at the beginning of the study and took place before the introduction of ACT.
Ciomed Central 


\section{Methods}

\section{Study area}

The study was conducted in Korogwe District, northeastern Tanzania. Korogwe District is about 100 kilometers inland from the coastal town, Tanga. It is a tropical area with two rainy seasons: April to June and October to December. January and February are normally dry, but recently there have been climatic changes with merging of these two rainy seasons. Entomological surveys in the study area have shown that Anopheles gambiae is the most prevalent vector in the lowlands, while Anopheles funestus predominates in the highlands. In previous studies, entomological inoculation rates (EIR) have been reported to be more than 100 in the lowlands, but less than 30 infective bites per person per year at intermediate altitudes. In the highlands, mosquito densities are too low to allow reliable EIR measurements, but an EIR of 0.03 infective bites per person per year has been extrapolated [19]. There is no recent entomology data for the area, the most recent were collected in the late $1990 \mathrm{~s}$. Plasmodium falciparum is the dominant malaria parasite with Plasmodium malariae being encountered occasionally. Villagers perceive malaria as a major health problem among both children and adults leading to disease and deaths.

The study was conducted in two villages, Mkokola and Kwamasimba, which had 2,000 and 1,800 inhabitants, respectively in 2003. Mkokola village is situated at an altitude of about 300 meters above sea level (lowland village) and Kwamasimba at an altitude of approximately 700 meters (highland village). The two villages are approximately 15 kilometres apart [20-22].

\section{Longitudinal detection of febrile episodes}

In January 2003, management of uncomplicated malaria cases by trained village health workers was introduced into the study villages. The village health workers, locally called Community Owned Resource Persons (CORPS) carried out passive case detection of subjects with fever. There were two CORPS in each village, one of whom was always present in the village, so that any village resident who had a febrile illness, had an opportunity to obtain treatment at any time. The CORPS were provided with thermometer, first-line anti-malarial drugs (sulphadoxine-pyrimethamine [SP] up to 2006 and artemether-lumefantrine [ALu] from 2007 to date), paracetamol, slides, blood lancets, gloves, treatment charts, febrile case detection forms and storage boxes. CORPS were instructed how to collect blood smears under aseptic technique and to preserve these until collected by a team of supervisors composed of a clinical officer and a laboratory technician. CORPS were also instructed on how to treat patients with the first-line anti-malarial drug and an antipyretic, and how to refer patients who had severe symptoms or who did not respond adequately to the first-line anti-malarial treatment to Korogwe District Hospital. Villagers were informed that they could call on the CORPS at any time if they had symptoms of malaria. From suspected malaria cases, the CORPS would then collect basic clinical data, obtain a blood smear for malaria microscopy and institute presumptive malaria treatment. Patients with severe symptoms or symptoms suggestive of other diseases than malaria were referred to the local dispensary or the District Hospital.

\section{Cross-sectional surveys}

Malaria cross-sectional surveys were conducted in the two study villages from 2003 to 2008 (Table 1). The surveys were conducted in May during the main rainy season in the years 2003-2008, and just before the short rains in November in the years 2003-2007. During each cross-sectional survey, demographic data were collected together with a history of migration and recent travel. The reported use of a bed net was also recorded. A history of recent illness was obtained, emphasizing symptoms suggestive of malaria. Physical examination for signs related to malaria, such as temperature, pulse, spleen size, pallor or a raised respiratory rate was conducted. Axillary temperature was measured using digital thermometers. For any individual diagnosed with a mild disease, appropriate drugs were administered.

Five millilitres of venous blood were collected from individuals aged three years or more. For children below three years, 300-400 $\mu \mathrm{l}$ of capillary blood was obtained by finger prick into an Eppendorf tube containing EDTA. The haemoglobin $(\mathrm{Hb})$ concentration of each participant was measured using a $\mathrm{HemoCue}^{\bullet}$ photometer (Ångelholm, Sweden). Whole blood was used to prepare thick and thin blood smears for malaria microscopy. These were stained with $10 \%$ Giemsa stain for 15-20 minutes after fixing thin smears with methanol. Asexual and sexual parasites were counted against 200 and 500 white blood cells, respectively. The differentiation of malaria parasite species was confirmed by microscopy of thin smears. A blood smear was declared negative only after examination of 200 high power fields. The density of asexual parasites was calculated assuming 8,000 leucocytes per $\mu \mathrm{l}$ of blood and expressed as parasites per $\mu \mathrm{l}$. Slides were red retrospectively and during surveys malaria treatment was only given to patients complaining of malaria symptoms.

\section{Data management and analysis}

All data were double-entered into a Microsoft Access database, cleaned, validated and transferred into Stata version 9 (Stata Corporation, Texas, USA) and R 2.7.0 for statistical analysis. Fever was defined as an observed 
Table 1 Number of participants surveyed per village per year

\begin{tabular}{|c|c|c|c|c|c|c|c|}
\hline \multirow[t]{2}{*}{ Village } & \multirow[t]{2}{*}{ Age group (years) } & \multicolumn{6}{|c|}{ Number of participants surveyed per year } \\
\hline & & 2003 & 2004 & 2005 & 2006 & 2007 & 2008 \\
\hline \multirow[t]{9}{*}{ Lowland village } & $<1$ & 30 & 15 & 20 & 30 & 23 & 5 \\
\hline & 1 & 35 & 48 & 55 & 34 & 35 & 21 \\
\hline & 2 & 31 & 63 & 61 & 52 & 14 & 20 \\
\hline & 3 & 29 & 45 & 79 & 52 & 20 & 7 \\
\hline & 4 & 26 & 47 & 63 & 70 & 23 & 20 \\
\hline & $5-9$ & 76 & 157 & 191 & 212 & 130 & 59 \\
\hline & $10-14$ & 47 & 65 & 153 & 56 & 165 & 49 \\
\hline & $15-19$ & 36 & 52 & 55 & 18 & 58 & 22 \\
\hline & Total & 310 & 492 & 677 & 524 & 468 & 203 \\
\hline \multirow[t]{9}{*}{ Highland village } & $<1$ & 25 & 23 & 42 & 33 & 34 & 5 \\
\hline & 1 & 25 & 51 & 80 & 50 & 44 & 14 \\
\hline & 2 & 20 & 53 & 73 & 72 & 40 & 17 \\
\hline & 3 & 29 & 32 & 77 & 47 & 60 & 15 \\
\hline & 4 & 28 & 56 & 58 & 67 & 48 & 20 \\
\hline & $5-9$ & 81 & 160 & 123 & 220 & 207 & 55 \\
\hline & $10-14$ & 44 & 63 & 75 & 90 & 141 & 52 \\
\hline & $15-19$ & 31 & 54 & 46 & 28 & 40 & 34 \\
\hline & Total & 283 & 492 & 574 & 607 & 614 & 212 \\
\hline
\end{tabular}

axillary temperature of $\geq 37.5^{\circ} \mathrm{C}$ and/or a history of fever within the previous 24 hours. A febrile malaria episode was defined as an episode of fever with a positive blood smear for asexual Plasmodium falciparum parasitaemia of any density. The summary measures consisted of percentage for categorical variables and means for continuous variables. Incidence was calculated as documented number of febrile malaria episodes to the population size in each age group and/or village per year.

In modelling the risk of Plasmodium falciparum, parasiteamia across the years, number of individuals with parasitaemia during cross-sectional surveys were modelled as a binomial random variable using logistic regression. The model was fitted for each village separately and was adjusted for the effect of age and use of bednets. To compare the risk of Plasmodium falciparum infection between the two villages, a similar model was fitted for the two villages. In addition, linear regression models were used to determine the changes in mean haemoglobin $(\mathrm{Hb})$ concentration across years and effect of Plasmodium falciparum parasiteamia and season on $\mathrm{Hb}$ levels while controlling for age and reported use of insecticide-treated or non-treated bed nets. In this model the effect of year was fitted as a categorical variable. A statistical significance level was considered at P-value $<0.05$.

\section{Ethical considerations}

Ethical clearance was granted by the Medical Research Co-ordinating Committee of the National Institute for Medical Research, Tanzania. Prior to the study, meetings were held with local authorities and with the villagers in each study village, during which the aims of the study were explained. Informed consent documents for the study were prepared in English and translated into Kiswahili before administration to both village leaders and participants. Written informed consent to participate was obtained from each study individual or from his or her parent or guardian. Villagers were free not to participate in the study without giving any reasons, or being disqualified from any medical services that were provided to all villagers throughout the study period. Feedback to the village has been performed continuously during the study.

\section{Results}

Malaria parasitaemia by year

At the first cross-sectional survey, $P$. falciparum was detected in $78 \%$ and $25 \%$ of the residents of lowland and highland villages, respectively. In the subsequent cross-sectional surveys conducted each year, the prevalence of $P$. falciparum decreased steadily in both villages as shown Figures 1 and 2. The risk of $P$. falciparum infection was higher in residents of lowland village, OR $=12.28$ (95\%CI: $9.44-15.10, \mathrm{p}<0.001)$ compared to highland village. The risk of infection decreased by year, with an OR of 0.564 (95\% CI: 0.526-0.605, p < 0.001) and 0.660 (95\% CI: 0.602-0.730, p < 0.001), per year compared with the baseline, for lowland and highland villages, respectively. The decline in the point prevalence of parasiteamia was seen in all age groups in both villages (Figure 3), but was most pronounced among one 


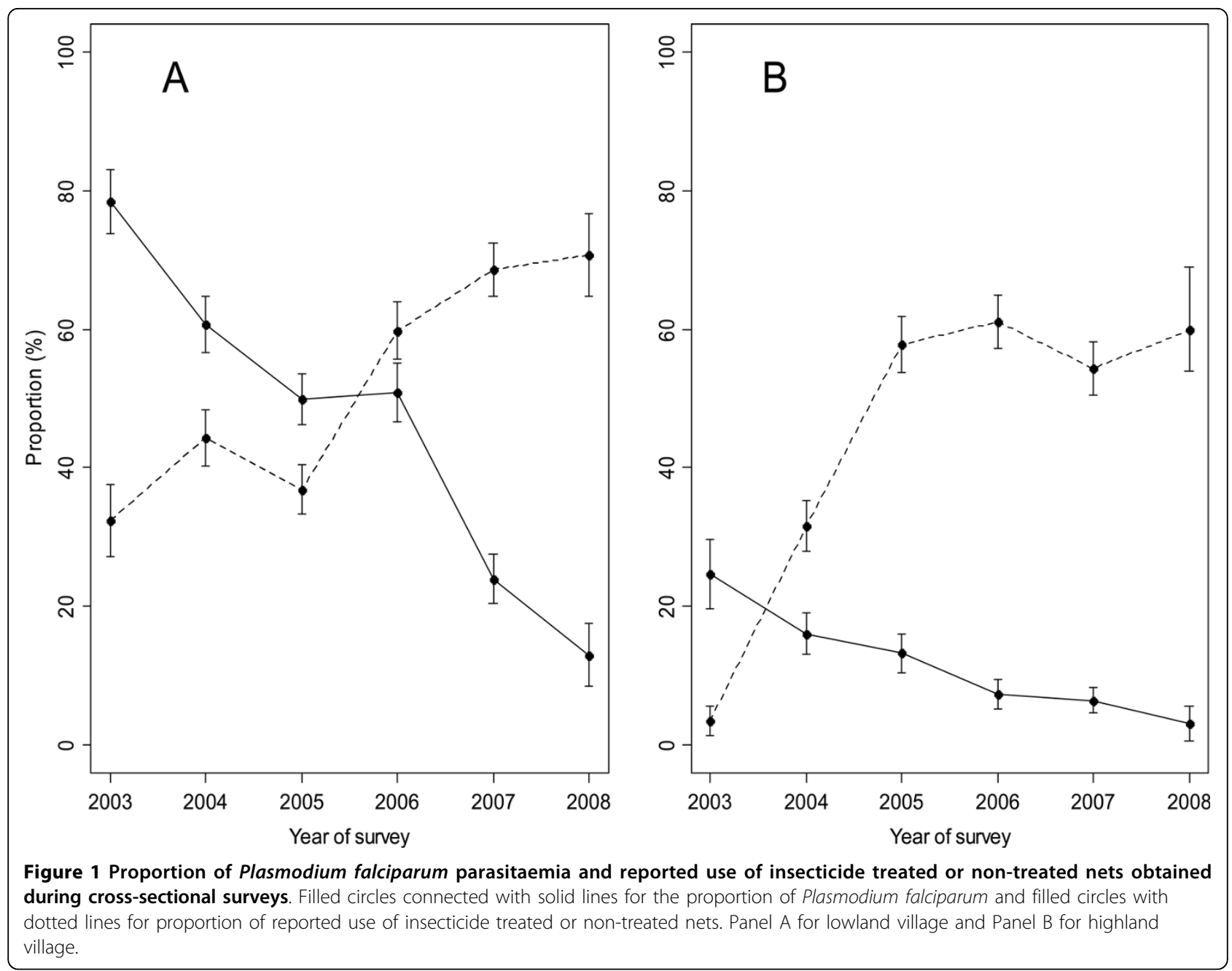

to three year old children in the high transmission village (lowland village). During the study, reported use of both impregnated nets and/or non-impregnated bed net increased from $32 \%$ to about $80 \%$ in the high transmission village (lowland village) and from $4 \%$ to about $60 \%$ in the low transmission village (highland village).

Use of a bed nets was associated with a reduction in the risk of parasitaemia OR $=0.666$ (95\%CI: $0.575-0.770, \mathrm{p}$ $<0.001)$. When the effect of the use of bed nets was assessed in each village separately, it was found that the use of bed nets was not associated with a reduction in the risk of malaria parasitaemia in highland village $(\mathrm{OR}=$ 0.921 (95\%CI: $0.708-1.198, \mathrm{p}=0.540)$, but was significant in lowland village $(\mathrm{OR}=0.572$ (95\%CI: 0.479 0.681, $\mathrm{p}<0.001$ ).

\section{Incidence of febrile malaria episodes by age}

The age specific incidence of malaria episodes by village is shown in Figure 4. Children below five years in lowland village had a higher incidence than children in highland village throughout. The incidence of episodes of malaria (per 1,000 person years) among children under five years of age declined dramatically in both villages during the 2003-2008 study period from 649.0 (95\%CI:548.3 - 768.3) to 33.6 (95\%CI:25.5 - 44.4), and 368.9 (95\%CI:297.5 - 457.4) to 16.8 (95\%CI:11.7 - 24.0) in lowland and highland villages, respectively. The decrease in incidence was most marked during the first three years of the study and there was only a minor difference in incidence between 2006 and 2008. This was the case in individuals of all ages and in both villages.

\section{Haemoglobin concentration by year}

The mean haemoglobin concentration of individuals living in highland village was higher than that of those living in lowland village. In highland village, mean haemoglobin concentration was highest in 2003, whereas in lowland village it was the lowest in this year. Similarly, the mean haemoglobin concentration of children aged 0-3 from lowland village was markedly lower 


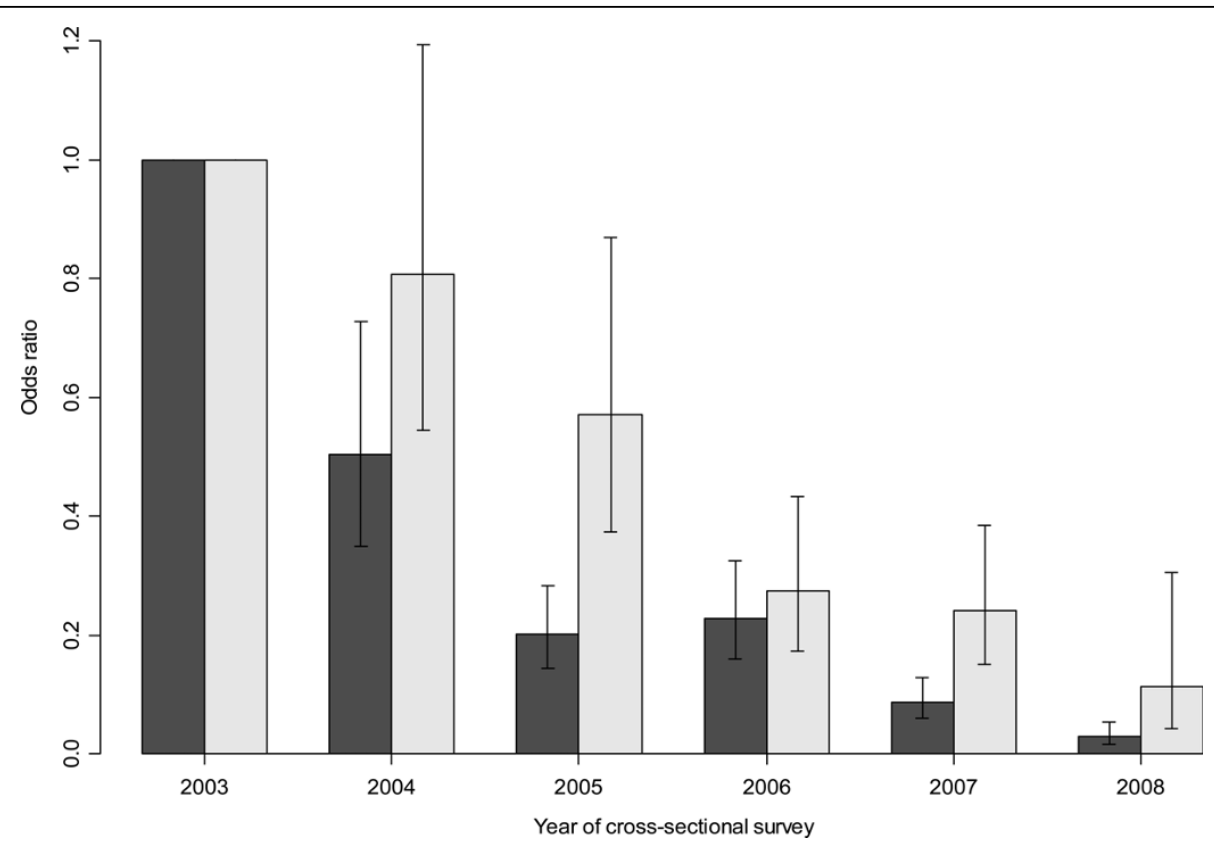

Figure 2 Odds ratio of Plasmodium falciparum parasite adjusted for age, bed nets use and season of survey from 2003-2008, with 2003 as a baseline. Filled and open bars are for lowland and highland villages, respectively.

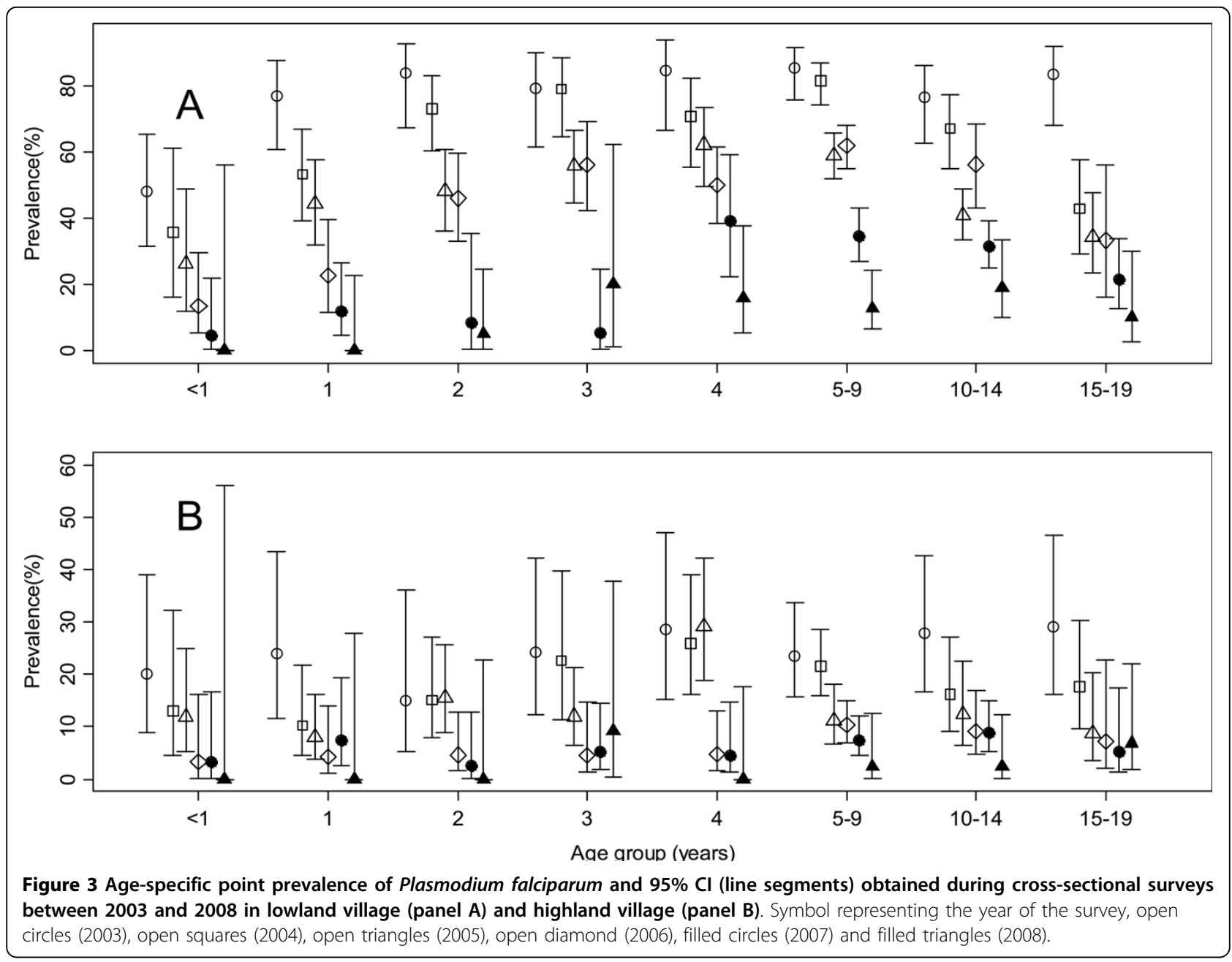




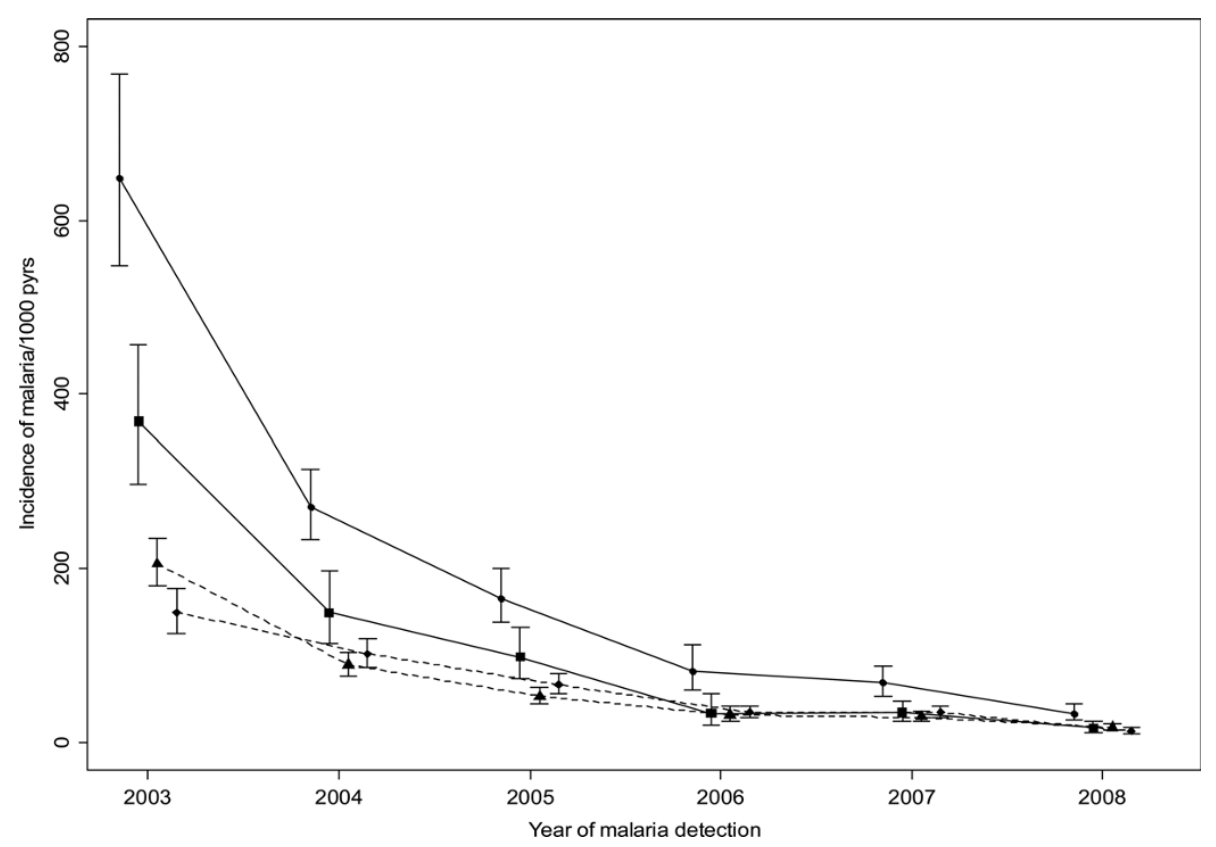

Figure 4 The incidence of febrile malaria episodes among residents of lowland village (filled circles and triangles) and highland village (filled squares and diamonds) between $\mathbf{2 0 0 3}$ and 2008. Full lines represent children $<5$ years, while dashed lines are individuals aged $\geq 5$ years.

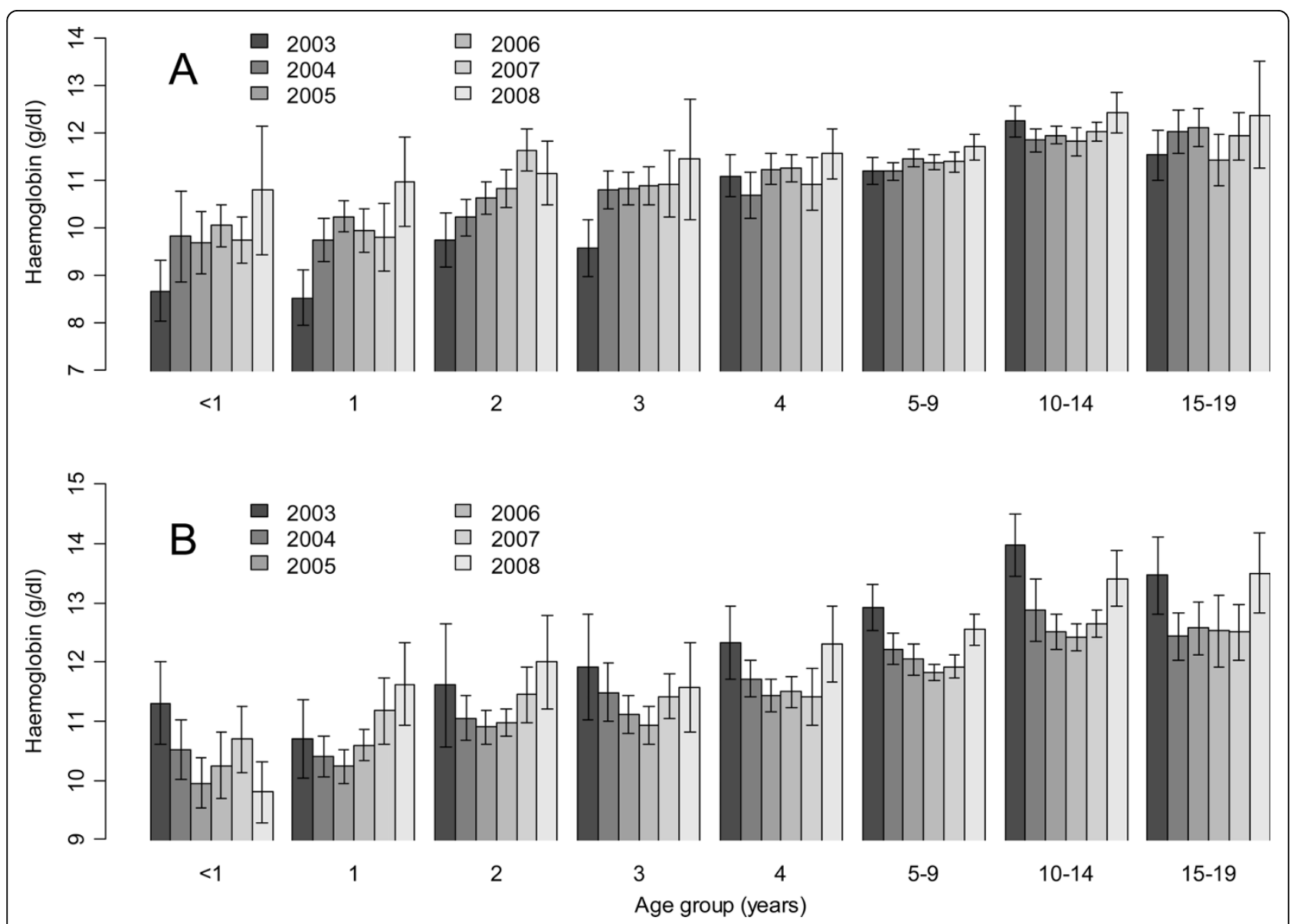

Figure 5 Age-specific mean haemoglobin concentration (g/dl) measured during cross-sectional surveys between 2003 and 2008 in lowland (A) and highland (B) villages, respectively. Graduated grey colour shows year of survey and line segments represent $95 \% \mathrm{Cl}$. 
in 2003 than in the following years (Figure 5). Adjusting for effect of age and sex, there was a trend to increasing mean haemoglobin concentration in lowland village by year (Table 2). Contrarily, the mean haemoglobin was significantly lower in highland village in all surveys conducted in 2004-2008 compared to one in 2003, (Table 2 and Figure 5). In lowland village, use of bed nets had no apparent effect on mean haemoglobin concentration while in highland village it was associated with a significantly increase in mean haemoglobin by $0.149 \mathrm{~g} / \mathrm{dl}$. In both villages, the presence of Plasmodium falciparum parasitaemia was associated with a lower mean haemoglobin concentration (Table 2).

\section{Discussion}

This community based study assessed the malaria burden in two villages in Korogwe district, north-eastern Tanzania by collecting data in repeated cross-sectional surveys and by employing CORPS to monitor malaria morbidity over six consecutive years. In this study, lowland residents had almost a twelve-fold increase in the risk of malaria parasitaemia compared to their counterparts in the highland village. At the start of the study, the lowland village could be categorized as high transmission whereas transmission in the highland village could be categorized as moderate. During the six years of the study, there was a marked and progressive decline in the malaria burden and this was reflected in the point prevalence of parasitaemia, the incidence of clinical episodes of malaria and in the mean haemoglobin concentration.

It is well established that immunity to malaria is a function of age, and that in areas of high transmission the malaria burden mainly is carried mainly by children and infants, while in areas of low transmission, all age groups are affected [23]. As malaria transmission declined in the study area, a change in the age distribution of the malaria burden was detected. In 2003, young children resident in the high transmission village had a markedly higher incidence of malaria fevers than older children and young adults, and many of these children were anaemic. Indeed, the most striking finding of this study was the pronounced increase in the haemoglobin concentrations among 1-3 year old children in the lowland village. This represents a remarkable health gain and underscores findings of previous studies showing the high impact malaria has on haemoglobin levels in young children in areas of high transmission $[15,24,25]$

During the study, the malaria burden also decreased among inhabitants of highland village and among the older age groups in lowland village, but because the decline in burden was more pronounced among the young children in lowland village, the net effect was that, at the end of the study the malaria burden appeared to be more equally distributed among the different age groups. During the study, many cases of severe malaria were not documented. This is probably due to the fact that a relatively low number of individuals were surveyed, and that these individuals had access to prompt and effective treatment. Thus, how the decline in transmission has affected the incidence of severe malaria in its different manifestations could not be estimated. This, is an important question as cerebral malaria has been reported to affect slightly older children than those affected by severe anaemia, and a declining incidence might lead to an increase in this severe form of malaria $[14,26]$.

Other studies mainly based on data collected at health facilities have documented that malaria transmission seems to be falling in other parts of East Africa and in some of these studies the decrease has been attributed

Table 2 Linear regression results showing the change in mean haemoglobin concentration (g/dL) in highland and lowland villages by year and other variables when adjusted for age and gender

\begin{tabular}{|c|c|c|c|c|c|c|}
\hline \multirow[b]{2}{*}{ Variable } & \multicolumn{3}{|c|}{ Lowland village } & \multicolumn{3}{|c|}{ Highland village } \\
\hline & Coefficient & $(95 \% \mathrm{Cl})$ & P-value & Coefficient & $(95 \% \mathrm{Cl})$ & P-value \\
\hline Intercept & 9.253 & $(8.822-9.684)$ & $<0.001$ & 11.073 & $(10.652-11.494)$ & $<0.001$ \\
\hline Use of net & 0.039 & $(-0.075-0.153)$ & 0.495 & 0.149 & $(0.031-0.267)$ & 0.013 \\
\hline P. falciparum ${ }^{\S}$ & -0.388 & $(-0.506--0.27)$ & $<0.001$ & -0.471 & $(-0.642--0.300)$ & $<0.001$ \\
\hline Survey period & -0.28 & $(-0.400--0.160)$ & $<0.001$ & -0.254 & $(-0.374--0.134)$ & $<0.001$ \\
\hline Year 2003 & Reference & & & & & \\
\hline Year 2004 & 0.145 & $(-0.065-0.355)$ & 0.175 & -0.933 & $(-1.154--0.712)$ & $<0.001$ \\
\hline Year 2005 & 0.327 & $(0.129-0.525)$ & 0.001 & -1.199 & $(-1.42--0.978)$ & $<0.001$ \\
\hline Year 2006 & 0.286 & $(0.076-0.496)$ & 0.008 & -1.248 & $(-1.469--1.027)$ & $<0.001$ \\
\hline Year 2007 & 0.134 & $(-0.087-0.355)$ & 0.235 & -1.048 & $(-1.269--0.827)$ & $<0.001$ \\
\hline Year 2008 & 0.424 & $(0.130-0.718)$ & 0.005 & -0.515 & $(-0.821--0.209)$ & $<0.001$ \\
\hline
\end{tabular}

$\S$ Blood slide positivity for Plasmodium falciparum at sampling

\# Effect of blood sample collected in November versus May 
to specific interventions [14-18]. In this community based study, a dramatic decrease in malaria indices in the absence of specific interventions other than giving villagers access to treatment through trained village helpers is documented. During the first four years of the study period, the first-line anti-malarial was SP, but from January 2007 an ACT was used. Thus, the most dramatic decrease in malaria burden took place when $\mathrm{SP}$, a drug to which there is widespread resistance in the area, was in use [27]. Although the presumptive treatment of febrile cases could have played a role in reducing transmission[28], this could not explain the findings. In 2005, World Vision deployed many nets in Korogwe, including the study villages. Although the coverage was not complete, there has been a substantial increase in use of nets in the study villages, approaching $60 \%$. It has been argued that communal effect of protection is achieved when coverage reaches $64 \%$, which is almost the case in these villages [26], but again whether nets at the coverage reached could have had such pronounced effects on transmission as indicated by the decrease in point prevalence from 2003 to 2008 is still debatable. As in Tanzania in general, there has been a steady socio-economic development in the area, but there have not been major changes or investments in infrastructure in the two study villages that can explain the decrease in malaria morbidity.

There is no simple explanation for the decline in malaria in the study villages, and it is rather an unsatisfactory situation of having to assign this to a combination of different factors such as climatic changes, better health provision, increased coverage of bed nets and socio economical development. It is very important to establish the relative contribution of these and other factors to the decline in malaria, as this will shed light on the risk that malaria might strike back. Entomological studies in the study villages were not done during the study period and whether there have been changes in mosquitoes distribution across years is not established.

In conclusion, there has been a dramatic progressive decline in point prevalence of malaria in the study villages during the study period, and in parallel the malaria disease burden has fallen, especially among those most affected previously, the infants and young children living in the village where malaria transmission was high previously.

\footnotetext{
Acknowledgements

The authors are grateful to the dedicated study teams which conducted cross-sectional surveys through data collection and processing. They also acknowledge discussion made and contributed by Michael Alifrangis, Pamela Magistrado, Samuel Gesase, Daniel Minja, Chris Drakeley and Deus Ishengoma. Technical and logistics supports of Ezekiel Malecela, Juma Akida, Dominick Shauri, Thomson Mwampamba, Rashid Madebe, Tilaus Gustav, Johari Sadi, Sia Minja, Eva Nyenza, Silas Msangi, Aneth Goso, Stella
}

Mkandawile, Julius Mhache and Allan Mrango are highly appreciated. Authors remain indebted to the study participants for their time and endurance throughout the process. Brian Greenwood is acknowledged for reviewing the final manuscript. DANIDA and Gates Malaria Partnership are acknowledged for financial support.

\section{Author details}

${ }^{1}$ National Institute for Medical Research, Tanga Centre, Tanga, Tanzania. ${ }^{2}$ Department of Biostatistics, University of Copenhagen, Copenhagen, Denmark. ${ }^{3}$ Centre for Medical Parasitology at Department of International Health, Immunology and Microbiology, University of Copenhagen, and Department of Infectious Diseases, Copenhagen University Hospital (Rigshospitalet), Copenhagen, Denmark. ${ }^{4}$ Special Programme for Research \& Training in Tropical Diseases (TDR), World Health Organization, Geneva, Switzerland.

\section{Authors' contributions}

All authors were involved in the design of the study. LV, BM, AK, ML, $\Pi$ and $J \mathrm{~L}$ conceived the study. BM, LV and $J$ and were responsible for the implementation of the study in the field. BM coded the data and supervised data entry. BM and $J \mathrm{~L}$ analysed data. $J \mathrm{~L}$ wrote the first draft of the manuscript. All authors were involved in revising the manuscript, and read and approved the final version.

\section{Competing interests}

The authors declare that they have no competing interests.

Received: 2 February 2010 Accepted: 23 July 2010

Published: 23 July 2010

\section{References}

1. White NJ, Nosten F, Looareesuwan S, Watkins WM, Marsh K, Snow RW Kokwaro G, Ouma J, Hien TT, Molyneux ME, Taylor TE, Newbold Cl, Ruebush TK, Danis M, Greenwood BM, Anderson RM, Olliaro P: Averting a malaria disaster. Lancet 1999, 353:1965-1967.

2. Breman JG: The ears of the hippopotamus: manifestations, determinants, and estimates of the malaria burden. Am J Trop Med Hyg 2001, 64:1-11.

3. Snow RW, Guerra CA, Noor AM, Myint HY, Hay SI: The global distribution of clinical episodes of Plasmodium falciparum malaria. Nature 2005, 434:214-217.

4. Molineaux L, Gramiccia G: The Garki Project: Research on the Epidemiology and Control of Malaria in the Sudan Savanna of West Africa Geneva, World Health Organization 1980.

5. Yamey G: Roll Back Malaria: a failing global health campaign. BMJ 2004 328:1086-1087.

6. Lengeler C: Insecticide-treated bednets and curtains for preventing malaria. Cochrane Database Syst Rev 2000, CD000363.

7. Alonso PL, Sacarlal J, Aponte JJ, Leach A, Macete E, Milman J, Mandomando I, Spiessens B, Guinovart C, Espasa M, Bassat Q, Aide P, OforiAnyinam O, Navia MM, Corachan S, Ceuppens M, Dubois MC, Demoitie MA, Dubovsky F, Menendez C, Tornieporth N, Ballou WR, Thompson R, Cohen J: Efficacy of the RTS,S/ASO2A vaccine against Plasmodium falciparum infection and disease in young African children: randomised controlled trial. Lancet 2004, 364:1411-1420.

8. Bejon $\mathrm{P}$, Lusingu J, Olotu A, Leach A, Lievens M, Vekemans J, Mshamu S, Lang T, Gould J, Dubois MC, Demoitie MA, Stallaert JF, Vansadia P, Carter T, Njuguna P, Awuondo KO, Malabeja A, Abdul O, Gesase S, Mturi N, Drakeley CJ, Savarese B, Villafana T, Ballou WR, Cohen J, Riley EM, Lemnge MM, Marsh K, von Seidlein L: Efficacy of RTS,S/AS01E vaccine against malaria in children 5 to 17 months of age. N Engl J Med 2008, 359:2521-2532.

9. Lusingu JP, Gesase S, Msham S, Francis F, Lemnge M, Seth M, Sembuche S, Rutta A, Minja D, Segeja MD, Bosomprah S, Cousens S, Noor R, Chilengi R, Druilhe P: Satisfactory safety and immunogenicity of MSP3 malaria vaccine candidate in Tanzanian children aged 12-24 months. Malar J 2009, 8:163.

10. Guyatt HL, Noor AM, Ochola SA, Snow RW: Use of intermittent presumptive treatment and insecticide treated bed nets by pregnant women in four Kenyan districts. Trop Med Int Health 2004, 9:255-261.

11. Nganda RY, Drakeley C, Reyburn H, Marchant T: Knowledge of malaria influences the use of insecticide treated nets but not intermittent 
presumptive treatment by pregnant women in Tanzania. Malar J 2004, 3:42.

12. Schellenberg D, Menendez C, Kahigwa E, Aponte J, Vidal J, Tanner M, Mshinda H, Alonso P: Intermittent treatment for malaria and anaemia control at time of routine vaccinations in Tanzanian infants: a randomised, placebo-controlled trial. Lancet 2001, 357:1471-1477.

13. Creasey A, Giha H, Hamad AA, El Hassan IM, Theander TG, Arnot DE: Eleven years of malaria surveillance in a Sudanese village highlights unexpected variation in individual disease susceptibility and outbreak severity. Parasitology 2004, 129:263-271.

14. Okiro EA, Hay Sl, Gikandi PW, Sharif SK, Noor AM, Peshu N, Marsh K, Snow RW: The decline in paediatric malaria admissions on the coast of Kenya. Malar J 2007, 6:151.

15. O'Meara WP, Bejon P, Mwangi TW, Okiro EA, Peshu N, Snow RW, Newton CR, Marsh K: Effect of a fall in malaria transmission on morbidity and mortality in Kilifi, Kenya. Lancet 2008, 372:1555-1562

16. Bhattarai A, Ali AS, Kachur SP, Martensson A, Abbas AK, Khatib R, Al Mafazy AW, Ramsan M, Rotllant G, Gerstenmaier JF, Molteni F, Abdulla S, Montgomery SM, Kaneko A, Bjorkman A: Impact of artemisinin-based combination therapy and insecticide-treated nets on malaria burden in Zanzibar. PLoS Med 2007, 4:e309.

17. Graves PM, Osgood DE, Thomson MC, Sereke K, Araia A, Zerom M, Ceccato P, Bell M, Del Corral J, Ghebreselassie S, Brantly EP, Ghebremeskel T: Effectiveness of malaria control during changing climate conditions in Eritrea, 1998-2003. Trop Med Int Health 2008, 13:218-228.

18. Biai S, Rodrigues A, Gomes M, Ribeiro I, Sodemann M, Alves F, Aaby P Reduced in-hospital mortality after improved management of children under 5 years admitted to hospital with malaria: randomised trial. BMJ 2007, 335:862

19. Bodker R, Akida J, Shayo D, Kisinza W, Msangeni HA, Pedersen EM, Lindsay SW: Relationship between altitude and intensity of malaria transmission in the Usambara Mountains, Tanzania. J Med Entomol 2003, 40:706-717.

20. Lusingu JP, Jensen AT, Vestergaard LS, Minja DT, Dalgaard MB, Gesase S, Mmbando BP, Kitua AY, Lemnge MM, Cavanagh D, Hviid L, Theander TG: Levels of plasma immunoglobulin $G$ with specificity against the cysteine-rich interdomain regions of a semiconserved Plasmodium falciparum erythrocyte membrane protein 1, VAR4, predict protection against malarial anemia and febrile episodes. Infect Immun 2006, 74:2867-2875.

21. Mmbando BP, Segeja MD, Msangeni HA, Sembuche SH, Ishengoma DS, Seth MD, Francis F, Rutta AS, Kamugisha ML, Lemnge MM: Epidemiology of malaria in an area prepared for clinical trials in Korogwe, northeastern Tanzania. Malar J 2009, 8:165.

22. Drakeley CJ, Carneiro I, Reyburn H, Malima R, Lusingu JP, Cox J, Theander TG, Nkya WM, Lemnge MM, Riley EM: Altitude-dependent and -independent variations in Plasmodium falciparum prevalence in northeastern Tanzania. J Infect Dis 2005, 191:1589-1598.

23. Reyburn H, Mbatia R, Drakeley C, Bruce J, Carneiro I, Olomi R, Cox J, Nkya WM, Lemnge M, Greenwood BM, Riley EM: Association of transmission intensity and age with clinical manifestations and case fatality of severe Plasmodium falciparum malaria. JAMA 2005, 293:1461-1470.

24. Massaga JJ, Kitua AY, Lemnge MM, Akida JA, Malle LN, Ronn AM, Theander TG, Bygbjerg IC: Effect of intermittent treatment with amodiaquine on anaemia and malarial fevers in infants in Tanzania: a randomised placebo-controlled trial. Lancet 2003, 361:1853-1860.

25. Schellenberg D, Menendez C, Aponte JJ, Kahigwa E, Tanner M, Mshinda H, Alonso P: Intermittent preventive antimalarial treatment for Tanzanian infants: follow-up to age 2 years of a randomised, placebo-controlled trial. Lancet 2005, 365:1481-1483.

26. Killeen GF, Smith TA, Ferguson HM, Mshinda H, Abdulla S, Lengeler C, Kachur SP: Preventing childhood malaria in Africa by protecting adults from mosquitoes with insecticide-treated nets. PLoS Med 2007, 4:e229.

27. Alifrangis M, Lemnge MM, Ronn AM, Segeja MD, Magesa SM, Khalil IF, Bygbjerg IC: Increasing prevalence of wildtypes in the dihydrofolate reductase gene of Plasmodium falciparum in an area with high levels of sulfadoxine/pyrimethamine resistance after introduction of treated bed nets. Am J Trop Med Hyg 2003, 69:238-243.
28. Gosling RD, Drakeley CJ, Mwita A, Chandramohan D: Presumptive treatment of fever cases as malaria: help or hindrance for malaria control? Malar J 2008, 7:132.

doi:10.1186/1475-2875-9-216

Cite this article as: Mmbando et al:: A progressive declining in the burden of malaria in north-eastern Tanzania. Malaria Journal 2010 9:216.

\section{Submit your next manuscript to BioMed Central and take full advantage of:}

- Convenient online submission

- Thorough peer review

- No space constraints or color figure charges

- Immediate publication on acceptance

- Inclusion in PubMed, CAS, Scopus and Google Scholar

- Research which is freely available for redistribution

Submit your manuscript at www.biomedcentral.com/submit
Biomed Central 